\title{
Self-Efficacy and Self-Regulation as the Predictors of Use of Oral Communication Strategies in EFL Contexts
}

Hamideh Abbasi, Mania Nosratinia*

Islamic Azad University, Central Tehran Branch, Iran

Corresponding Author: Mania Nosratinia, E-mail: mania_nosratinia@yahoo.com

\section{ARTICLE INFO}

Article history

Received: January 07, 2018

Accepted: March 12, 2018

Published: July 01, 2018

Volume: 7 Issue: 4

Advance access: May 2018

Conflicts of interest: None

Funding: None

\begin{abstract}
The present study aspired to systematically investigate the relationship among EFL learners' Self-Regulation (SR), Self-Efficacy (SE), and their Use of Oral Communication Strategies (UOCS). To this end, 367 male and female undergraduate students, within the age range of 20 to $30\left(M_{\text {age }}=25\right)$ were selected based on convenience sampling strategy. They were asked to fill in three questionnaires, namely the Oral Communication Strategies Inventory (Nakatani, 2006), the Motivated Strategies for Learning Questionnaire (Pintrich, Smith, Garcia, \& McKeachie, 1991), and the SE Questionnaire (Sherer, Maddux, Mercadante, Prentice-Dunn, Jacobs, \& Rogers, 1982). Both parametric and non-parametric formulas were conducted to inspect the significance of the relationships. The results revealed that there was a significant and positive correlation between SR and UOCS, SE and UOCS, and SE and SR. Furthermore, a regression analysis revealed that only SR makes a strong statistically significant unique contribution to predicting UOCS $(\beta=0.682, t=15.3, p=0.0005)$. SE did not turn out to be a significant predictor of UOCS scores. The study concludes with a discussion on the obtained results followed by presenting some implications for EFL teachers, learners, and syllabus designers.
\end{abstract}

Key words: Internal Factors, Oral Communication Strategies, Self-efficacy, Self-regulation, Speaking

\section{INTRODUCTION}

This study was an attempt to systematically inspect the way self-efficacy, self-regulation, and use of oral communication strategies, as major factors in learning (Luszczynska, Gutiérrez-Doña, \& Schwarzer, 2005; Skantze, 2005), interact with one another. A further goal of the study was to compare the predictive capacity of self-efficacy and self-regulation in terms of predicting use of oral communication strategies. Today, it is no longer unbeknownst to TEFL experts and scholars that the main function of language is to enable individuals to communicate ideas and information with other speakers of the language while highlighting comprehensibility and clarity (Lightbown \& Spada, 2013; Mitchell \& Myles, 2004). This awareness has been contemporaneous with the growing endorsement of the social constructivist theory which favors the active construction of language competence through a social and experiential process, highlighting the role of active and planned communication (Ashton-Hay, 2006; Zaker, 2016a, 2016b).

As EFL learners are always faced with a myriad of limitations when it comes to oral second language (L2) production, affecting the accuracy and fluency of the spoken L2 production (Mitchell \& Myles, 2004), techniques and strategies have been in use which enable the L2 speakers to compensate for the limitations they suffer (Ellis, 2008; Nakatani, 2005). Specifically calibrated for addressing L2 production issues, oral communication strategies have been defined as "potentially intentional attempts to cope with any language-related problems of which the speaker is aware during the course of communication" (Dörnyei \& Scott, 1977, p. 179). These strategies help EFL learners obviate communicative problems (Bialystok, 1990; Dörnyei, 1995).

Oral communication strategies are categorized into two main groups, achievement and reduction strategies (Tarone, 1981). Regardless of the group to which each strategy belongs, they are all the components of the mental construct which, by nature, correlates with and is affected by the unique cognitive, metacognitive, and personality characteristics of each single individual (Fahim \& Zaker, 2014; Marashi \& Moghaddam, 2014). Moreover, many of these internal factors are subject to change and manipulation (Fahim \& Zaker, 2014; Zaker, 2016a), making it reasonable to attempt to develop and strengthen a construct indirectly and through other related constructs. In other words, it might enhance our knowledge of oral communication strategies and provide us with the chance to indirectly manipulate it if we study the way this construct interacts with other constructs. Rooted in the above-mentioned penchant, this descriptive study intended to systematically inspect the way self-effica- 
cy, self-regulation, and use of oral communication strategies interact among EFL learners.

As stated by Pintrich (2000), self-regulation is "an active constructive process whereby learners get goals for their learning and then attempt to monitor, regulate, and control their cognition, motivation, behavior, guided and constrained by their goals and the contextual features in the environment" (p. 453). Self-regulation, as a metacognitive process, is a major factor in determining learners' motivational states and communicative efforts (Zimmerman, 2000). It has been stated that the manipulation and development of self-regulation functions as an effective measure to develop use of oral communication strategies among EFL learners (Zimmerman, 2000, 2008) and improve their speaking performance (Aregu, 2013). Consequently, it is reasonable to inspect if there exists a significant relationship between use of oral communication strategies and self-regulation so that oral communication can be promoted through self-regulation instruction.

Self-efficacy, the other inspected mental construct in this study, has been defined as "personal judgment of one's capabilities to organize and execute course of action to attain designated type of educational performance" (Bandura, 1977 , p. 174). Quite reasonably, it has been suggested that self-efficacy is a crucial factor in determining EFL learners' communicative efforts in L2 (Abedini \& Rahimi, 2009), and it can function as a motivational construct which affects the application of strategies, including oral communication strategies (Schunk, 1994). Therefore, it is sensible to inspect if the self-perceived image of the learners, or their self-efficacy should be one of the concerns when attempting to develop the quality of L2 production among EFL learners (Aregu, 2013; Chiu-Ping, 2010).

Pertinent to the abovementioned premises, previous research has suggested that self-efficacy and self-regulation are in a direct relationship with use of oral communication strategies and can affect each other (Aregu, 2013; Pintrich, 1995; Zimmerman \& Schunk, 2001). More specifically, according to Zimmerman (1989), self-efficacy should be considered one of the components of self-regulation. Rooted in this background, it could be another goal for the present study to inspect the existence of this relationship. Finally, it becomes of high value to educational policy makers, curriculum developers, teacher trainers, and teachers to realize if there is an association among the three variables introduced so far and, if so, between self-efficacy and self-regulation which one is the better choice for investing time, energy, and resources in order to develop EFL learners' communication skills.

Rooted in the penchant for coming up with new pedagogical solutions for developing EFL learners' oral communication skills, this study intended to systematically inspect the way use of oral communication strategies, self-efficacy, and self-regulation interact among EFL learners. To fulfill this purpose, the following research questions were formulated:

Research Question 1: Is there any significant relationship between EFL learners' self-regulation and their use of oral communication strategies?
Research Question 2: Is there any significant relationship between EFL learners' self-efficacy and their use of oral communication strategies?

Research Question 3: Is there any significant relationship between EFL learners' self-efficacy and self-regulation? Research Question 4: Is there any significant difference between EFL learners' self-regulation and self-efficacy in predicting their use of oral communication strategies?

\section{METHOD}

\section{Participants}

The participants of the present study were 367 undergraduate male and female (110 or $30 \%$ male and 257 or $70 \%$ female) EFL learners, within the age range of 20 to 30 $\left(M_{a g e}=25\right)$, studying TEFL, English Translation, and English Literature at Islamic Azad University (Central Tehran, South Tehran, and Science and Research Branches) and Aal-e-Taha University in Tehran. The sampling strategy for the selection of the participants was convenience sampling. It should be noted that the initial number of participants was 402 , but 35 of them were excluded from the data due to providing incomplete answers, bringing the final number to 367 participants.

\section{Instrumentation}

In order to collect the quantitative data and fulfill the purpose of the study, the following instruments were employed:

- The Motivated Strategies for Learning Questionnaire

- The Oral Communication Strategy Inventory

- The Self-Efficacy Questionnaire

\section{Pintrich, Smith, Garcia, and McKeachie's MSLQ Questionnaire}

To estimate the level of participants' self-regulation, the Motivated Strategies for Learning Questionnaire (MSLQ), developed by Pintrich, Smith, Garcia, and McKeachie (1991) was used. The MSLQ is a self-report survey instrument designed to assess college students' motivational orientations and use of different learning strategies. The original form of MSLQ has 81 Likert-scale statements, from 1 "not at all true of me" to 7 "very true of me", within 15 modular subscales divided into two categories: Motivation (6 subscales) and Learning Strategies (9 subscales).

The total scores of the instrument could vary from 81 to 567 , and the respondents were asked to answer the questions in 35 minutes. The psychometric properties of this scale also have been well-established at different educational levels (Garcia \& McKeachie, 2005; Pintrich et. al., 1991, 1993; Wolters, Pintrich, \& Karabenick, 2005). The MSLQ has proved reliable and valid in several studies (Garcia \& Pintrich, 1994, 1995; Kivinen, 2002; Pintrich, Smith, Garcia, \& McKeachie, 1993). In this study, the reliability of the MSLQ was computed through Cronbach alpha at 0.8 . 


\section{Nakatani's OCSI Questionnaire}

Nakatani (2006) developed the Oral Communication Strategy Inventory (OCSI) for EFL university students. This instrument aims to assess the frequency with which the students use certain strategies in oral communication while coping with speaking problems in L2 communicative tasks. As Nakatani (2006) stated, both speaking and listening skills are essential for oral communication. They involve strategies of a different nature. Therefore, the inventory con-sists of 58 statements divided into two sections: strategies for coping with speaking problems related to strategic behavior during communicative tasks (32 items) and strategies for coping with listening problems related to strategic behavior at comprehension during communicative tasks (26 items).

The participants were expected to respond on the fivepoint Likert-scale ranging from 1 "never or almost never true of me" to 5 "always or almost always true of me" that asked them to report the frequency with which they use certain strategies in oral communication to compensate for the problems. The allocated time for responding to the items of the questionnaire is 30 minutes, and the scores could vary from 58 to 290. In a study conducted by Nakatani (2006), utilizing Cronbach's alpha, the reliability of the speaking section was estimated to be $r=.838$ and $r=.905$ for the listening part. In this study, the reliability of the OCSI was computed through Cronbach alpha at 0.87 .

\section{Sherer, Maddux, Mercadante, Prentice-Dunn, Jacobs, and Rogers'Self-Efficacy Scale}

To evaluate participants' level of self-Efficacy, the English version of the Self-Efficacy Questionnaire developed by Sherer, Maddux, Mercadante, Prentice-Dunn, Jacobs, and Rogers (1982) was administered. It consists of 23 items which measure three aspects of behavior: initiative, effort, and persistence. It has two subscales; the general self-efficacy (17 items) and the social self-efficacy (6 items). Participants respond on the basis of a five-point Likert-scale, ranging from strongly disagree (1 point) to strongly agree (5 points).

The scores range from 23 to 115 , and the allocated time is 15 minutes. Scores for Items 1, 3, 8, 9, 13, 15, 19, 21, 23 correspond to the answer and remaining items are scored in reverse direction. Obtained score lower than 45 is characterized as low self-efficacious, between 46 and 70 moderate, and score more than 71 is known as having high self-efficacy. The reliability of the self-efficacy scale in this study was estimated to be 0.81 , using the Cronbach's alpha coefficient.

\section{Procedure}

To achieve the purpose of this study and address the questions posed, the researchers followed the following procedure. After obtaining a formal approval for conducting the research at the universities where the data were collected, the three questionnaires of were distributed in one package among 402 undergraduate EFL learners in the above-mentioned universities.
Before administering the packages of the questionnaires, the researchers intentionally randomized the order of the questionnaires in each package to control the impact of order on the completion process. The required explanations were given to the participants. Also, the researchers mentioned that the results of the questionnaires would be just used for the sake of the academic value of this research. The procedures in filling all three questionnaires were also explained. The allocated time for answering the three questionnaires was about 80 minutes, and the completed questionnaires were collected and scored by the researchers. From the initial 402 administered questionnaires, a number of 367 sets answered for three questionnaires, were considered for statistical analyses regarding the relationship among the three variables.

\section{RESULTS}

The design of this study was descriptive. The predicted variable was use of oral communication strategies and the predictors were self-efficacy and self-regulation. Moreover, participants' age and gender were considered the intervening variables. In order for the researchers to answer the research questions, a series of pertinent calculations and statistical routines were conducted whose results are presented in this section.

\section{The Preliminary Analyses}

Before answering the research questions, it was needed to check a number of assumptions and perform some preliminary analyses. To begin with, the assumptions of interval data and independence of participants (Tabachnick \& Fidell, 2007) were already met as the present data were measured on an interval scale and the participants were independent of one another. In addition, it was needed to check some other significant assumptions through inspecting the features of the data. These assumptions, according to Tabachnick and Fidell (2007), are:

1. Linear relation between each pair of variables,

2. Homoscedasticity, and

3. Normality of the distribution of variables.

The following sections will check the three abovementioned assumptions which are pertinent to the first, second, and third research questions of the study. However, as the legitimacy of addressing the fourth research question is dependent on the answers given to the three initial research questions, the preliminary analyses pertinent to the fourth research question are reported after addressing the first three research questions.

\section{Linear Relation between Each Pair of Variables and Homoscedasticity}

To check the linearity of relations, the researchers visually inspected the data through creating a multiple scatterplot which is presented in Figure 1.

Through inspecting Figure 1, it can be inferred that the relationships among these variables are not fundamentally 
non-linear. As it can be observed, there is not a U-shaped or curvilinear pattern of distribution. Consequently, the linearity of relations can be confirmed. Moreover, the distribution of scores was not funnel-shape, i.e., wide at one end and narrow at the other; therefore, the assumption of homoscedasticity was met for these variables.

\section{Normality of the Distributions}

In order to check the normality of the distributions, first, the kurtosis and skewness ratios were calculated, followed by inspecting the distribution histograms and Normal Q-Q Plots. However, as the main measure, the Kolmogorov-Smirnov test was run, results of which are presented in Table 1.

As presented in Table 1, the Sig. value for the scores of oral communication strategies $(.0005)$ is lower than the crit-

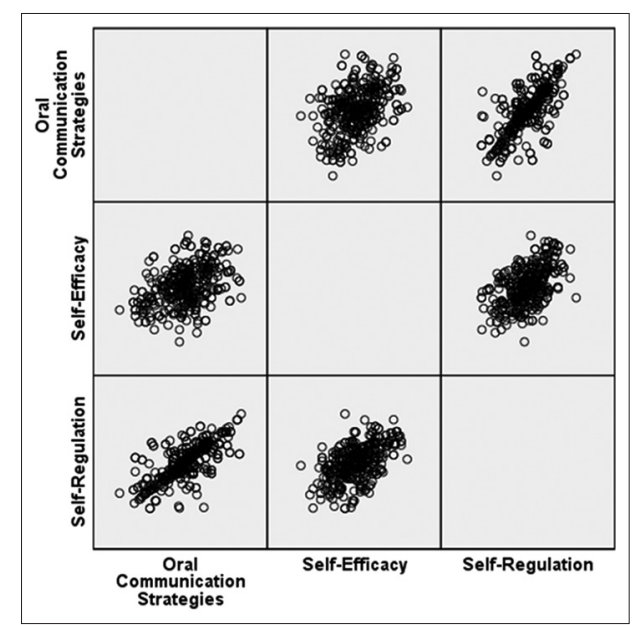

Figure 1. Multiple scatterplot of oral communication strategies, self-efficacy, and self-regulation ical value (.05). Therefore, only the normality of distribution for self-efficacy and self-regulation scores is supported (Tabachnick \& Fidell, 2007). Consequently, it was systematically suggested that the assumption of normality is violated for the scores of oral communication strategies. Therefore, the correlational research questions including oral communication strategies (research questions one and two) were answered through employing a non-parametric test, Spearman rank order coefficient of correlation. In order to answer the third research question, the data were analyzed using Pearson's product-moment correlation coefficient, a parametric formula.

\section{Answering the Three Initial Research Questions}

\section{The First Research Question}

In order to answer the first research question, the data were analyzed using the Spearman rank order coefficient of correlation which is a non-parametric formula. Table 2 shows the result of this analysis.

According to the results of the analysis reported in Table 2, it was concluded that there was a significant and positive correlation between self-regulation and use of oral communication strategies, $\rho=.705, n=367, p<.01$, and high levels of self-regulation were associated with high levels of use of oral communication strategies. According to Cohen (1988), this signified a large effect size (99\% confidence intervals: 0.631 to 0.766 ).

\section{The Second Research Question}

In order to answer the second research question, the data were analyzed using the Spearman rank order coefficient of correlation. Table 3 shows the result of this analysis.

Table 1. Tests of normality of the scores

\begin{tabular}{|c|c|c|c|c|c|c|}
\hline & \multicolumn{3}{|c|}{ Kolmogorov-smirnov ${ }^{a}$} & \multicolumn{3}{|c|}{ Shapiro-wilk } \\
\hline & Statistic & df & Sig. & Statistic & df & Sig. \\
\hline Oral communication strategies & 0.071 & 367 & 0.000 & 0.989 & 367 & 0.009 \\
\hline Self-efficacy & 0.036 & 367 & $0.200^{*}$ & 0.995 & 367 & 0.256 \\
\hline Self-regulation & 0.036 & 367 & $0.200 *$ & 0.993 & 367 & 0.106 \\
\hline
\end{tabular}

a. Lilliefors significance correction, ${ }^{*}$. This is a lower bound of the true significance.

Table 2. Spearman's correlation between oral communication strategies and self-regulation

\begin{tabular}{lcc}
\hline & Oral communication strategies & Self-regulation \\
\hline Spearman's rho & & \\
Oral communication strategies & 1.000 & $0.705^{* *}$ \\
Correlation coefficient & & 0.000 \\
Sig. (2-tailed) & 367 & 367 \\
N & & 1.000 \\
Self-regulation & $0.705^{* *}$ & 367 \\
Correlation coefficient & 0.000 & 367 \\
Sig. (2-tailed) & 367 \\
N
\end{tabular}

**Correlation is significant at the 0.01 level (2-tailed). 
Table 3. Spearman's correlation between oral communication strategies and self-efficacy

\begin{tabular}{lcc}
\hline & Oral communication strategies & Self-regulation \\
\hline Spearman's rho & & \\
Oral communication strategies & & $0.399^{* *}$ \\
Correlation coefficient & 1.000 & 0.000 \\
Sig. (2-tailed) & $\cdot$ & 367 \\
N & 367 & 1.000 \\
Self-regulation & $0.399 * *$ &. \\
Correlation coefficient & 0.000 & 367 \\
Sig. (2-tailed) & 367 & \\
N &
\end{tabular}

**Correlation is significant at the 0.01 level (2-tailed).

Table 4. Spearman's correlation between self-efficacy and self-regulation

\begin{tabular}{lcc}
\hline & Self-Efficacy & Self-regulation \\
\hline Self-efficacy & 1 & $0.541^{* *}$ \\
Pearson correlation & & 0.000 \\
Sig. (2-tailed) & 367 & 367 \\
$\mathrm{~N}$ & & \\
Self-regulation & $0.541^{* *}$ & \\
Pearson correlation & 0.000 & 367 \\
Sig. (2-tailed) & 367 \\
$\mathrm{~N}$ & & \\
\hline$* *$ Correlation is significant at the 0.01 level (2-tailed).
\end{tabular}

According to the results of the analysis reported in Table 3 , it was concluded that there was a significant and positive correlation between self-efficacy and use of oral communication strategies, $\rho=.399, n=367, p<.01$, and high levels of self-efficacy were associated with high levels of use of oral communication strategies. According to Cohen (1988), this signified a medium-to-large effect size $(99 \%$ confidence intervals: 0.28 to 0.506$)$.

\subsubsection{The Third Research Question}

In order to answer this question, the data were analyzed using Pearson's product-moment correlation coefficient, a parametric formula. Table 4. shows the result of this analysis.

According to the results of the analysis reported in Table 4 , it was concluded that there was a significant and positive correlation between self-efficacy and self-regulation, $r=.571, n=367, p<.01$, and high levels of self-efficacy were associated with high levels of self-regulation. According to Cohen (1988), this signified a large effect size $(99 \%$ confidence intervals: 0.439 to 0.629 ).

Based on the findings of the three initial research questions, both self-efficacy and self-regulation were significantly and positively related to use of oral communication strategies. In other words, self-efficacy and self-regulation significantly interact with use of oral communication strategies among EFL learners. As a result, the researchers could opt for answering the fourth research question, considering self-efficacy and self-regulation the predictor variables of the predicted variable, use of oral communication strategies.

\section{Preliminary Analyses Pertinent to the Fourth Research Question}

The fourth research question of this study was answered through running a multiple regression analysis. However, there were a number of assumptions which had to be checked before performing the analysis. According to Tabachnick and Fidell (2007), these assumptions are:

1. Sample size

2. Multicollinearity

3. Normality

4. Outliers

Employing Tabachnick and Fidell's (2007) formula for calculating sample size $(N>50+8 m)$ indicated that this assumption was met as 367 is way above the minimum required number of 66 participants. Furthermore, the researchers implemented some measures in order to systematically inspect the existence of multicollinearity in the sample, the Tolerance value and VIF value. Table 5 reports the Tolerance and VIF values in this study.

As reported in Table 5, both of the Tolerance values were desirably higher than.1. Moreover, the VIF values were desirably lower than 10. Therefore, it was concluded that, as required, multicollinearity did not exist in this sample. Furthermore, in order to check the normality, the Normal Probability Plot (P-P) was created which suggested no major deviation from normality. Furthermore, the scatterplot of standardized residuals showed that residuals were rectangularly distributed.

Finally, the researchers inspected the Mahalanobis distance value in order to notice and inspect the existence of outliers. According to Tabachnick and Fidell (2007), when there are two independent variables in the model, the critical value for the Mahalanobis value is 13.28. This means that if the Mahalanobis value for a variable is larger than 13.28, that case is an outlier. According to the initial analysis result, the highest Mahalanobis value in this sample was 13.58 which is above the critical level. The inspection of the data indicated that the case 131 has the Mahalanobis value of 
13.57607, making it the only outlier case. Consequently this case was removed from the data, and the rest of the analyses were carried out on the data obtained from 366 participants. After removing the outlier case, the new highest Mahalanobis value in the sample was 11.36, and the Cook's Distance values were, desirably, smaller than the critical value 1 . As a result, the researchers could argue that the assumption pertinent to the outliers is met.

\section{The Fourth Research Question}

In order to answer the fourth research question, a standard multiple regression was run. Table 6 presents the regression model summary including the $R$ and $R^{2}$.

As reported in Table 6, $R$ came out to be 0.706 and $R^{2}$ came out to be 0.498 . This means that the model explains 49.8 percent of the variance in use of oral communication strategies (Cohen, Cohen, West, \& Aiken, 2003). Moreover, $f^{2}=.992$ indicated a large effect size for the regression. Table 7 reports the results of $\operatorname{ANOVA}(F(2,363)=179.986$, $p=0.0005)$, the results of which were considered significant. This means that the model can significantly predict EFL

Table 5. Tolerance and VIF values

\begin{tabular}{lcc}
\hline Model & \multicolumn{2}{c}{ Collinearity statistics } \\
\cline { 2 - 3 } & Tolerance & VIF \\
\hline 1 & & \\
(Constant) & & \\
Self-efficacy & 0.708 & 1.413 \\
Self-regulation & 0.708 & 1.413 \\
\hline
\end{tabular}

learners' use of oral communication strategies, self-efficacy, and self-regulation.

Table 8 demonstrates the Standardized Beta Coefficients which signify the degree to which each predictor variable contributes to the prediction of the predicted variable. The inspection of the Sig. values showed that only self-regulation makes a statistically significant unique contribution to the equation as its Sig. values is less than.05.

Self-regulation seemed to have the only Sig. value smaller than.05 with the absolute $\beta$ coefficient of.68 $(\beta=0.682$, $t=15.3, p=0.0005)$. This means that self-regulation makes a strong statistically significant unique contribution to predicting use of oral communication strategies. Therefore, it was concluded that, compared to self-efficacy, self-regulation is the best factor which can significantly predict use of oral communication strategies scores of the participants. Self-efficacy did not turn out to be a significant predictor of use of oral communication strategies scores $(\beta=0.041, t=$ $0.924, p=0.365)$. Finally, the inspection of Part correlation (semipartial correlation coefficient) revealed that self-regulation uniquely explains 32.37 percent of the variance in use of oral communication strategies $(0.569 \times 0.569=0.3237)$.

\section{DISCUSSION}

The first research question of the study attempted to systematically inspect the relationship between EFL learners' use of oral communication strategies and self-regulation, the latter being considered a major factor in determining learners' metacognitive attempts and motivational states (Zimmerman, 2000). The results of the Spearman rank order coefficient of correlation indicated that there was a significant and positive

Table 6. Model summary $-\mathrm{R}$ and $\mathrm{R}$ square

\begin{tabular}{lcccc}
\hline Model & $\mathbf{R}$ & R square & Adjusted R square & Std. error of the estimate \\
\hline 1 & $0.706^{\mathrm{a}}$ & 0.498 & 0.495 & 18.43553 \\
\hline a. Predictors: (Constant), Self-regulation, self-efficacy, b. Dependent variable: Oral communication strategies &
\end{tabular}

Table 7. Regression output: ANOVA

\begin{tabular}{|c|c|c|c|c|c|}
\hline Model & Sum of squares & df & Mean square & $\mathbf{F}$ & Sig. \\
\hline \multicolumn{6}{|l|}{1} \\
\hline Regression & 122343.081 & 2 & 61171.540 & 179.986 & $0.000^{\mathrm{a}}$ \\
\hline Residual & 123372.419 & 363 & 339.869 & & \\
\hline Total & 245715.500 & 365 & & & \\
\hline
\end{tabular}

a. Predictors: (Constant), self-regulation, Self-efficacy, b. Dependent variable: Oral communication strategies

Table 8. Regression output: coefficients

\begin{tabular}{|c|c|c|c|c|c|c|}
\hline \multirow[t]{2}{*}{ Model } & \multicolumn{2}{|c|}{$\begin{array}{c}\text { Unstandardized } \\
\text { coefficients }\end{array}$} & \multirow{2}{*}{$\begin{array}{c}\begin{array}{c}\text { Standardized } \\
\text { coefficients }\end{array} \\
\boldsymbol{\beta} \\
\end{array}$} & \multirow[t]{2}{*}{$\mathbf{T}$} & \multirow[t]{2}{*}{ Significance } & \multirow[t]{2}{*}{ Part correlation } \\
\hline & B & Std. error & & & & \\
\hline \multicolumn{7}{|l|}{1} \\
\hline (Constant) & 87.273 & 7.355 & & 11.867 & 0.000 & \\
\hline Self-efficacy & 0.084 & 0.091 & 0.041 & 0.924 & 0.356 & 0.034 \\
\hline Self-regulation & 0.304 & 0.020 & 0.682 & 15.300 & 0.000 & 0.569 \\
\hline
\end{tabular}


correlation (the largest in this study) between self-regulation and use of oral communication strategies, $\rho=.705, n=367$, $p<0.01$. This finding provides systematic support for the potential amplification of use of oral communication strategies through self-regulation training as suggested by Zimmerman (2000, 2008) and reported by Littlemore (2001). This finding is also in line with the framework of socio-cognitive learning theory, as stated by Pajares and Schunk (2001), which highlights the role of learners' cognition in social engagement and communicative attempts.

The systematic inspection of the relationship between use of oral communication strategies and self-efficacy among EFL learners was the concern of the second research question. As it has been suggested, self-efficacy is a crucial factor in determining EFL learners' communicative efforts in L2 (Abedini \& Rahimi, 2009). In a similar vein, Schunk (1994) suggests that self-efficacy as a motivational construct affects the application of strategies, including oral communication strategies. However, in order to confirm this argument, the researchers ran a Spearman rank order coefficient of correlation test whose results reported a significant and positive correlation between self-efficacy and use of oral communication strategies, $\rho=0.399, n=367, p<0.01$. This is in line with the argument provided by Pajaras (2000) and Zimmerman (1995). However, as the effect size of this correlational analysis turned out to be medium-to-large, it seems reasonable to argue that other studies should replicate this study in order to make a logical and meaningful conclusion about the existence of this positive correlation (Springer, 2010).

The third research question focused on the relationship between EFL learners' self-efficacy and self-regulation. Previous research has suggested that these two constructs are positively correlated (Bandura, 1997). It has also been suggested that high levels of self-regulation in EFL learners would be contemporaneous with high levels of self-efficacy (Pintrich, 1995; Zimmerman \& Schunk, 2001). In order to conduct a systematic probe, the researchers ran Pearson's product-moment correlation coefficient whose results reported a significant and positive correlation between self-efficacy and self-regulation, $r=.571, n=367, p<.01$. This outcome seems to provide a systematic support for the statements made by Bandura (1997), Pintrich (1995), and Zimmerman and Schunk (2001). Moreover, as the effect size turned out to be large, it seems that considering self-efficacy as one of the components of self-regulation, as suggested by Zimmerman (1989), is reasonable and meaningful. Moreover, it becomes more and more reasonable to argue for the causality of the relationship between these two constructs (Springer, 2010).

Having observed a significant and positive relationship between use of oral communication strategies, on one hand, and self-efficacy and self-regulation, on the other hand, it was legitimate for the researchers to inspect and compare how self-efficacy and self-regulation predict use of oral communication strategies among EFL learners. After checking the preliminary assumptions, a standard multiple regression was run whose results indicated that self-regulation makes the only statistically significant unique contribution to predicting use of oral communication strategies $(\beta=0.682)$. This is to say that self-regulation is the better predictor of use of oral communication strategies, and attempts to enhance the level of self-regulation, as suggested by Zimmerman (2000, 2008), have a higher potential to enhance EFL learners' use of oral communication strategies. However, as self-efficacy did not exhibit a significant predictive capacity toward use of oral communication strategies and knowing that self-efficacy and self-regulation share considerable features (Bandura, 1997), rejecting the predictive capacity of self-efficacy seems to be irrational before observing the same results in other studies replicating the present study (Best \& Kahn, 2006).

\section{CONCLUSION}

Around the world and among language educators, it is now a widely held belief that the major function of language is to enable individuals to communicate ideas and information with other speakers of the language (Mitchell \& Myles, 2004). However, when it comes to L2, the mixed impact of L1 and L2, materialized through the developed inter-language (Selinker, 1972), along with many other psychological, personality, cognitive, and metacognitive factors might affect or hinder one's success in getting the ideas across and cause problems like misunderstanding and making linguistic mistakes (Cohen \& Macaro, 2007; Zaker, 2016a). Initially introduced by Selinker (1972, as cited in Ellis, 2008), communication strategies are believed to be a set of conscious attempts used by L2 speakers which facilitate communication (Dörnyei, 1995; Theng, 2012).

More specifically, oral communication strategies help learners compensate for L2 problems, have more interaction in L2, have a conversation, and finally promote their communicative competence (Nakatani, 2005, 2010). These strategies have also proven to positively affect speakers' willingness to communicate (Sarvghadi, 2016). However, employing oral communication strategies, as a set of conscious cognitive and metacognitive attempts, is affected by the internal, cognitive, mental, and personality characteristics of the speakers (Marashi \& Moghaddam, 2014; Nosratinia \& Zaker, 2014; Zaker, 2015). Knowing that many of these internal factors are subject to change and manipulation (Dulewicz \& Higgs, 2004; Fahim \& Zaker, 2014), the present study aimed for inspecting the interaction of EFL learners' use of oral communication strategies, on one hand, and their self-efficacy and self-regulation, on the other hand, through posing four research questions.

Through answering the first research question of the study, it was systematically confirmed that self-regulation and use of oral communication strategies are in a significant direct relationship. In the wake of this finding, it seems reasonable to argue that the manipulation and development of self-regulation can be considered a significant measure to develop use of oral communication strategies among EFL learners, as suggested by Zimmerman (2000, 2008), and finally improve their speaking performance (Aregu, 2013). Through answering the second research question of the study, it was systematically confirmed that self-efficacy and use of oral communication strategies are significantly and positively correlated. This finding is in line with the stated 
argument provided by Pajaras (2000), Schunk (1994), and Zimmerman (1995). Consequently, a systematic support is provided for the argument that the self-perceived image of the learners, or their self-efficacy should be one of the concerns when attempting to develop the quality of L2 production among EFL learners (Aregu, 2013; Chiu-Ping, 2010).

As discussed above, self-efficacy and self-regulation both are in a direct relationship with use of oral communication strategies. This premise was confirmed through answering the third research question. Consequently, it is fair to expect that by developing EFL learners' self-efficacy, we can expect higher levels of self-regulation, and vice versa (Aregu, 2013; Pintrich, 1995; Zimmerman \& Schunk, 2001). Moreover, it seems that considering self-efficacy one of the components of self-regulation, as suggested by Zimmerman (1989), is reasonable and meaningful. From another perspective, now that both self-efficacy and self-regulation are in a direct relationship with use of oral communication strategies, it becomes of high value to educational policy makers, curriculum developers, teacher trainers, and teachers to realize between self-efficacy and self-regulation which one is the better choice for investing time, energy, and resources.

This question was addressed through answering the fourth/last research question of the study whose answer determined that self-regulation is the best predictor of EFL learners' use of oral communication strategies. Based on this outcome, it seems reasonable to argue that manipulating learners' self-regulation (O' Donnell, Reeve, \& Smith, 2012; Zimmerman, 2000) is one of the best tools for developing use of oral communication strategies, and special attention needs to be paid to cognitive, metacognitive, affective, and motivational as well as social contextual factors which predict and affect self-regulation (Pintrich, 2000).

Knowing that self-regulation is a significant predictor of use of oral communication strategies and that it is subject to development and training (Schunk, 1996; Zimmerman, 2000), EFL teachers should endeavor to allocate time for self-regulation training and implementation. According to Pintrich (2000), self-regulation consists of the following components:

- Cognitive,

- Metacognitive,

- Affective,

- Motivational, and

- Social contextual factors.

Considering the above-mentioned components, EFL teachers are suggested to:

- help learners manipulate various cognitive strategies for learning that a few of them are deep processing strategies (Garcia \& Pintrich, 1994),

- $\quad$ introduce and employ both top-down processes (cognitive control) and bottom-up processes (cognitive monitoring; Nelson \& Narens, 1990; Reder \& Schunn, 1996),

- guide learners to estimate their cognitive process and employ strategies which lead to the self-regulated achievement (Baker \& Brown, 1984),

- introduce emotion regulation which has a continuum from conscious, effortful, and controlled regulation to unconscious, effortless and automatic regulation. In fact, expressive suppression and reappraisal are two kinds of effective/emotion regulation strategies which are the major components of self-regulation (Balzarotti, John, \& Gross, 2010), and

- work on managing motivational beliefs including self-efficacy and goal-orientation (Zimmerman, 1989).

Moreover, EFL teachers can instruct EFL learners on employing oral communication strategies through (Faerch \& Kasper, 1983):

- helping EFL learners to obtain their conversation goals, especially in the classroom through implementing help-seeking strategies, negotiation signal strategies, output modification strategies, time-gaining strategies, and self-repairing strategies, and

- help learners to employ message abandonment strategies, first-language-based strategies, and inter-language-based reduction strategies.

Additionally, in order to help learners speak English more fluently, teachers may have to examine the possible effect of learner variables on the choice of oral communication strategies by the EFL learners, along with the impact of gender, language proficiency, self-perceived oral proficiency, the frequency of speaking English outside the classroom, and motivation in speaking English (Chiu-Ping, 2010). Furthermore, it might be possible to consider self-regulation test scores as one of the informing sources to determine the complexity and other features of the pedagogical tasks. Finally, EFL teachers should create an environment in which EFL learners feel comfortable and confident to participate in pedagogical tasks and, in this case, carry out the speaking and communication tasks with a lower level of anxiety and a higher level of concentration.

Along with highlighting the significance of learners' self-efficacy in developing their oral communication skills, the obtained results have clear implications for EFL learners when attempting to develop their communicative skills. In addition to active involvement in carrying out pedagogical tasks and activities and considering the components of self-regulation, EFL learners should:

- attempt to manipulate various cognitive strategies for learning, including processing strategies (Garcia \& Pintrich, 1994),

- $\quad$ attempt to learn and employ both top-down processes (cognitive control) and bottom-up processes (cognitive monitoring; Nelson \& Narens, 1990; Reder \& Schunn, 1996),

- try to estimate their cognitive process and employ strategies which lead to the self-regulated achievement (Baker \& Brown, 1984),

- implement emotion regulation (Balzarotti, John, \& Gross, 2010), and

- work on managing motivational beliefs including self-efficacy and goal-orientation (Zimmerman, 1989).

Moreover, EFL learners should attempt to employ oral communication strategies through (Faerch \& Kasper, 1983):

- implementing and employing help-seeking strategies, negotiation signal strategies, modifying output strategies, time-gaining strategies, and self-repairing strategies, and 
- employing message abandonment strategies, first-language-based strategies, and inter-language-based reduction strategies whenever it is appropriate.

Based on the findings of the present study, a statistically-supported justification is provided for paying a higher level of attention to EFL learners' internal factors and the process of strategy training, especially self-regulation training. EFL syllabi should provide the learners and teachers with a clear and comprehensible definition of self-regulation, its categories, and how it can be promoted and trained. Furthermore, EFL syllabi are recommended to pay attention to the main components of self-regulation, i.e. cognitive, metacognitive, affective, motivational, and social contextual factors (Pintrich, 2000). Concurrently, EFL syllabi should:

- introduce the different aspects of self-regulation and oral communication strategies,

- $\quad$ provide the learners and teachers with an objective criterion for evaluating their own self-regulation, and

- $\quad$ provide meaningful tasks through which teachers and learners focus on regulating the learning behavior.

Finally, dealing with oral communication strategies, EFL syllabi should directly and indirectly introduce the different categories of communication strategies, achievement and reduction strategies (Nakatani, 2005), and introduce the following strategies (Faerch \& Kasper, 1983):

- help-seeking strategies,

- negotiation signal strategies,

- output modification strategies,

- time-gaining strategies, and

- $\quad$ self-repairing strategies.

Based on the principles of descriptive research, the focus of the study, the characteristics of the participants, and the peculiarities of this study, there are a number of areas which were not touched in this study. Furthermore, other studies are required to inspect relevant concepts and confirm the results of this study. Accordingly, a limited number of recommendations are presented here, hoping that other researchers would find them interesting enough to pursue in the future.

a) This study can be replicated to find out whether the same results would be obtained or not.

b) It is suggested to replicate this study with equal numbers of male and female participants, so that gender might not act as an intervening variable.

c) It is suggested to compare the predictive power of self-regulation with other internal, personality, cognitive, and metacognitive factors in predicting use of oral communication strategies.

d) This study can be replicated employing some qualitative instruments to increase the validity and reliability of the results and interpretations.

e) The participants of the study were selected on the basis of convenience sampling. Other researchers can attempt to employ random sampling methods for replicating this study so that the validity of the findings is more defendable.

f) Within an experimental framework, other studies might endeavor to explore and study the comparative effect of self-efficacy and self-regulation training on EFL learners' use of oral communication strategies. g) Other studies can inspect the relationship between EFL teachers' self-regulation and EFL learners' self-regulation so that the impact of teachers' mental capacities on EFL learners is examined.

\section{REFERENCES}

Abedini, A, \& Rahimi, A. (2009). The interface between EFL learners' self-efficacy concerning listening comprehension and listening proficiency. Novitas-Royal, 3(1), 14-28.

Aregu, B. B. (2013). Enhancing self-regulated learning in teaching spoken communication: Does it affect speaking efficacy and performance? Electronic Journal of Foreign Language Teaching, 10(1), 96-109.

Ashton-Hay, S. (2006) Constructivism and powerful learning environments: Create your own! Paper presented at the $9^{\text {th }}$ International English Language Teaching Convention: The Fusion of Theory and Practice, Middle Eastern Technical University, Ankara, Turkey. Retrieved May 22, 2015, from http://eprints.qut.edu.au/17285/1/17285. pdf

Baker, L. \& Brown, A. L. (1984). Metacognitive skills and reading. In P. D. Pearson, R. Barr, M. L. Kamil \& P. Mosenthal (Eds.), Handbook of Reading Research (pp. 353-394). New York: Longman.

Balzarotti, S., John, O. P., \& Gross, J. J. (2010). An Italian adaptation of the emotion regulation questionnaire. European Journal of Psychological Assessment, 26, 61-67.

Bandura, A. (1977). Social learning theory. Englewood Cliffs, New Jersey: Prentice-Hall.

Best, J. W., \& Kahn, J. V. (2006). Research in education (10 ${ }^{\text {th }}$ ed.). Boston, MA: Pearson Education, Inc.

Bialystok, E. (1990). Communication strategies: A psychological analysis of second language use. London: Blackwell.

Chiu-Ping, H. (2010). Exploring factors affecting the use of oral communication strategies. Retrieved June 11, 2015, from http://www.lhu.edu. tw/m/oaa/synthetic/publish/publish/30/8.\%E9\%BB $\% 83 \%$ E7\%A7\%8B $\%$ E8\%90\%8D-Exploring\%20Factors $\% 20$ Affecting $\% 20$ the $\% 20$ Use $\% 20$ of $\% 20$ Oral $\% 20$ Communication $\% 20$ Strategies.pdf

Cohen, J. W. (1988). Statistical power analysis for the behavioral sciences ( $2^{\text {nd }}$ Ed.). Hillsdale, NJ: Lawrence Erlbaum Associates.

Cohen, J., Cohen, P., West, S. G., \& Aiken, L. S. (2003). Applied multiple regression/correlation analysis for the behavioral sciences ( $3^{\text {rd }}$ ed.). NJ: Lawrence Erlbaum Associates.

Cohen, A. D. \& Macaro, E. (2007). Language learner strategies: 30 years of research and practice. Oxford, UK: Oxford University Press.

Dörnyei, Z. (1995). On the teachability of communication strategies. TESOL Quarterly, 29(1), 55-85.

Dörnyei, Z., \& Scott, M. L. (1997). Communication strategies in a second language: Definitions and taxonomies. Language Learning. 47, 173-210.

Dulewicz, V., \& Higgs, M. (2004). Can emotional intelligence be developed? International Journal of Human Resource Management, 15(1), 95-111. 
Ehrman, M. (1996). An exploration of adult language learner motivation, self-efficacy and anxiety. In Oxford R. (Ed.) Language Learning Motivation: Pathways to the New Century (pp. 81-103). Honolulu: University of Hawaii Press.

Ellis, R. (2008). The study of second language acquisition. Oxford: Oxford University Press.

Erton, I. (2010). Relations between personality traits, language learning styles and success in foreign language achievement. Journal of Education, 38,115-126.

Faerch, C., \& Kasper, G. (1983). Plans and strategies in foreign language communication. In C. Faerch, \& G. Kasper (Eds.), Strategies in Interlanguage Communication (pp. 20-60). New York, USA: Longman.

Fahim, M. \& Zaker, A. (2014). EFL learners' creativity and critical thinking: Are they associated? Humanising Language Teaching, 16(3). Retrieved March 9, 2015, from http://www.hltmag.co.uk/jun14/mart01.htm

Garcia-Duncan, T. \& McKeachie, W. J. (2005). The Making of the Motivated Strategies for Learning Questionnaire. Educational Psychologist, 40, 117-128.

Garcia-Duncan, T., \& Pintrich, P. R. (1994). Regulating motivation and cognition in classroom. In D. H. Schunk, \& B. J. Zimmerman (Eds.), Self-regulation of Learning and Performance (pp. 127-154). Hillsdale, NJ: Erlbaum.

Kivinen, M. (2002). Progress and chaos. Russia as a challenge for sociological imagination. Helsinki: Kikimora Publications.

Lightbown, P., \& Spada, N. (2013). How languages are learned ( $4^{\text {th }}$ ed.). Oxford: Oxford University Press.

Littlemore, J. (2001). An empirical study of the relationship between cognitive style and the use of communication strategy. Oxford Journals. 22(2), 241-265.

Livingston, J. A. (1997). Metacognition: An overview. Retrieved August 2015 from: http://gse.buffalo.edu/fas/ shuell/CEP564/Metacog.htm

Luszczynska, A., Gutiérrez-Doña, B., \& Schwarzer, R. (2005). General self-efficacy in various domains of human functioning: Evidence from five countries. International Journal of Psychology, 40(2), 80-89.

Marashi, H. \& Moghadam, M. (2014). The differencs between field-dependent and field-independent EFL learners' critical thinking and use of oral communication strategies. International Journal of Language Learning and Applied Linguistics World), 7(3), 434-458.

Mitchell, R., \& Myles, F. (2004). Second language learning theories ( $2^{\text {nd }}$ ed.). London: Edward Arnold.

Nakatani, Y. (2005). The effects of awareness-raising training on oral communication strategy use. Modern Language Journal, 89 (1), 76-91.

Nakatani, Y. (2006). Developing an oral communication strategy inventory. The Modern Language Journal, 90 (2), 151-168.

Nakatani, Y. (2010). Identify strategies that facilitate EFL learners' oral communication: A classroom study using multiple data collection procedures. The Modern Language Journal, 94, 116-136.

Nelson, T. O., \& Narens, L. (1990). Metamemory: A theoretical framework and new findings. In G. Bower (Eds.),
The Psychology of Learning and Motivation (Vol. 26, pp. 125-173). New York: Academic Press.

Nosratinia, M., \& Zaker, A. (2014). Metacognitive attributes and liberated progress: The association among second language learners' critical thinking, creativity, and autonomy. SAGE Open, 4(3), 1-10. doi: 10.1177/2158244014547178.

O’ Donnell, A., Reeve, J., \& Smith, J. (2012). Educational psychology: Reflection for action ( $3^{\text {rd }}$ ed.). Hoboken, NJ: Wiley.

Pajares, F., \& Schunk, D. H. (2001). Self-beliefs and school success: Self-efficacy, selfconcept, and school achievement. In R. Riding, \& S. Rayner (Eds.), Self-perception (pp. 239- 266). London: Ablex Publishing.

Pintrich, P. R. (1995). Understanding self-regulated learning. New Directions for Teaching and Learning, 63, 3-12.

Pintrich, P. R. (2000). The role of goal orientation in self-regulated learning. In M. Boekaerts, P. R. Pintrich \& M. Zeidner (Eds.), Handbook of Self-Regulation (pp. 452-502). San Diego, CA: Academic Press.

Printrich, P. R., Smith, D. A., Garcia, T. \& McKeachie. W. J. (1991). A manual for the use of the Motivated Strategies for Learning Questionnaire (MSLQ). National Center for Research to Improve Postsecondary Teaching and Learning. Ann Arbor: University of Michigan.

Pintrich, P. R., Smith, D., Garcia, T., \& McKeachie, W. (1993). Reliability and predictive validity of the motivated strategies for learning questionnaire (MSLQ). Educational and Psychological Measurement, 53, 801-813.

Reder, L. Y., \& Schunn, C. D. (1996). Metacognition does not imply awareness: Strategy choice is governed by implicit learning and memory. In L. Y. Reder (Eds.), Implicit Memory and Metacognition (pp. 45-78). Mahah, NJ: Erlbaum.

Sarvghadi, Sh. (2016). The relationship among EFL learners' willingness to communicate, autonomy and use of oral communication strategies (Unpublished master's thesis). Islamic Azad University at Central Tehran, Iran.

Schunk, D. H. (1994). Self-regulation of self-efficacy and attributions in academic settings. In D. H. Schunk \& B. J. Zimmerman (Eds.), Self-regulation of learning and performance: Issues and educational applications (pp. 75-99). Hillsdale, NJ: Erlbaum.

Schunk, D. H. (1996). Goal and self-evaluaive influences during children's cognitive skill learning. American Editorial Research Journal, 33, 359-382.

Selinker, L. (1972). Interlanguage. International Review of Applied Linguistics, 10, 209-231.

Sherer, M., Maddux, J. E., Mercandante, B., Prentice-Dunn, S., Jacobs, B., \& Rogers, R. W. (1982). The Self-Efficacy Scale: Construction and validation. Psychological Reports, 51, 663-671.

Skantze, G. (2005). Exploring human error recovery strategies: Implications for spoken dialogue systems. Speech Communication, 45, 325-341.

Springer, K. (2010) Educational research: A contextual approach. Hoboken, NJ: Wiley.

Tabachnick, B. G., \& Fidell, L. S. (2007). Using multivariate statistics. Boston, MA: Pearson Education, Inc.

Tarone, E. (1981). Some thoughts on the notion of communication strategy. TESOL Quarterly, 15(3), 285-295. 
Theng, Y. L. (2012). Investigating effects of avatars on primary school children's affective responses to learning. Journal on Multimodal user interfaces, 5(1-2), 45-52.

Wolters, C. A., Pintrich, P. R., \& Karabenick, S. A. (2005). Assessing Academic Self- Regulated Learning. In K.A. Moore, L. H. Lippman, K. A. Moore, \& L. H. Lippman (Eds.), What do children need to flourish: Conceptualizing and measuring indicators of positive development (pp. 251-270). New York, NY US: Springer Science Business Media.

Zaker, A. (2015). EFL learners' language learning strategies and autonomous learning: Which one is a better predictor of L2 skills? Journal of Applied Linguistics-Dubai, 1(1), 27-39.

Zaker, A. (2016a). Social constructivism and metacognition in an EFL context: Inspecting the contribution of critical thinking to EFL learners' social intelligence. Humanising Language Teaching 18.6. Retrieved December 27, 2016, from www.hltmag.co.uk/dec16/index.htm

Zaker, A. (2016b). The acculturation model of second language acquisition: Inspecting weaknesses and strengths. Indonesian EFL Journal, 2(2), 80-87.
Zimmerman, B. J. (1989). A social cognitive view of self-regulated academic learning. Journal of Educational Psychology, 81 (3), 329-339.

Zimmerman, B. J. (1995). Self-regulation involves more than metacognition: A social cognitive perspective. $E d-$ ucational Psychologist, 30, 217-221.

Zimmerman, B. J. (2000). Attaining self-regulation: A social cognitive perspective. In M. Boekaerts, P.R. Pintrich, \& M. Zeidner (Eds.), Handbook of self-regulation (pp. 13-39). San Diego, CA: Academic Press.

Zimmerman, B. J. (2008). Investigating self-regulation and motivation: Historical background, methodological developments, and future prospects. Journal of American Educational Research, 45, 166-183.

Zimmerman, B. J. \& Schunk, D. H. (2001). Self-regulating intellectual processes and outcomes: A social cognitive perspective. In D. Y. Dai and R. J. Sternberg (Eds.), Motivation, Emotion, and Cognition: Integrative Perspectives on Intellectual Functioning and Development (pp. 143-174). Mahwah, NJ: Lawrence Erlbaum. 